\title{
OBITUARY.
}

\section{Ernest Matilakd.}

[Died July 19th, 1894.]

$\mathrm{I}^{\mathrm{N}}$ the history of scientific Mineralogy the name of M. Mallard will versally conceded the honour of originating this branch of human knowledge. His death took place at Paris, while he was in the apparent enjoyment of full health and vigour, at the age of 61 .

It may be asserted without exaggeration that M. Mallard created anew the science of crystallised bodies by bringing that science into close and intimate union with general physies. Only a few years ago mineralogy was regarded as a purely descriptive science, resembling zoology or botany, and crystallography was no more than a special chapter of abstract geometry. Yet a crystal is by no means simply a figure; it is a body possessing a certain structure to which the form is related.

What is this structure, and how is it to be referred to the laws of symmetry to which all crystallised substances are subject? This great problem had often been vaguely entertained, but its solution was presented by M. Mallard in a manner which leaves nothing to be desired.

In this subject he was the close follower of Bravais, whose beautiful theory he, to his great credit, adopted, developed and popularised. Bravais, however, viewed the problem as a geometrician, and saw only one side of the question. The conception of the lattice is based upon the homogeneity of the crystal. Now experience had long ago shown that crystals are far from being always homogeneous. To M. Mallard is due the honour of explaining this apparent contradiction by demonstrating theoretically and experimentally that crystals frequently consist of several lattices distributed in a certain regular manner about an axis which does not belong to any one of them. This luminous conception at once solved all difficulties of interpretation, for it reduced all the apparent exceptions to the operation of a universally accepted law, the general law of symmetry.

M. Mallard did more than this, and hereon rests his claim to imperishable fame. He deduced from the theory of lattices and of reticular assembleges all the physical phenomeua observed in crystallised bodies, 
including what were called the optical anomalies. Crystallography in the widest acceptation of the term, the study of crystallised bodies, had been nothing more than a purely empirical science. It became, owing to the labours of $M$. Mallard, a rompletely rational science to the same extent as any other branch of physics, for from that time it possessed a general principle, from which all the laws of the observed phenomena can be directly deduced.

The theories of M. Mallard have been, as is well known, energetically opposed, especially in Germany ; but this is the fate of all theories which open up new horizons, and for that very reason come as a shock to received ideas and established customs. They are, however, destined to spread more widely until they achieve their final triumph in scientific thonght, when the present generation, which has been educated in the school of purely geographical crystallography, shall have been replaced by a now one.

The crowning work of M. Mallard was his Traite de Cristallographie, which was intended to comprise three volumes. Two only of these have appeared, in 1879 and 1884 respectively. The first is devoted to the geometrical and the second to the physical characters of crystals. The last volume was to have dealt with crystalline assemblages, polymorphism and isomorphism:-the most complex problems in crystallography, and those in which his most original work was done.

It is much to be regretted in the cause of science that the last and long-expected volume has not been published, but the materials from which it was to be constructed are to be found dispersed through the numerous memoirs issued by M. Mallard since 1879. Some of these memoirs are real masterpieces, and have become classical, such as the papers on optical anomalies, on the quasi-cubic form of all crystallised bodies, on the transformations of polymorphous substances, and on isomorphous mixtures. All these works are distinguished by a remarkable conciseness of style and lucidity of expression. On every page are to be found new ideas, brilliant generalisations and an altogether exceptional accuracy of observation.

Endowed with a powerful intellect and the spirit of the acute observer, M. Mallard excelled in that difficult art by which a problem is confined within its true sphere, is referred to a general scientific principle, and is solved without the aid of any hypothesis.

When in addition to the above-mentioned works relating to the general problems of erystallography we add the many detailed researches which he published in the Bulletin of the French Mine- 
logical Bociety, some relating to improved instruments of precision, and some to particular mineral species, such as boleite, lussatite, tridymite, and melanophlogite, we cannot but feel that since the time of Haüy no one has done so much to advance that section of physical science which is concerned with crystallised bodies.

G. WrrodBofr. 